\title{
Wound complications following modified radical mastectomy: An analysis of perioperative factors
}

\author{
RICHARD A. HOEFER, JR, LT COL, USAR MC \\ JEFFREY J. DUBOIS, MAJ, USAF MC \\ LOUIS B. OSTROW, MAJ, USAF MC \\ LINDA FULLER SILVER, RN, BSN
}

To assess the effect of perioperative factors on the incidence of postoperative wound complications, the authors retrospectively analyzed $101 \mathrm{pa}$ tients who had undergone modified radical mastectomy. These factors included age, body weight, operative techniques, estimated blood loss, wound-catheter drainage, extent of axillary dissection, nodal involvement, and length of hospital stay. Complications included seroma (10.9\%), wound infection $(8.9 \%)$, wound necrosis $(5 \%)$, hematoma $(3 \%)$, lymphedema $(2 \%)$, and pneumothorax $(1 \%)$. The logistic regression method was used to analyze the data. When electrocautery was used to create the skin flaps, the probability of a wound complication was .462 , a $44 \%$ increase over that calculated for the coldknife technique $(P=.05)$. A prolonged hospitalization accompanied the occurrence of a wound complication. No other factors reached statistical significance.

From the department of general surgery, David Grant USAF Medical Center, Travis Air Force Base, Calif.

The viewpoints presented in this article are those of the authors and do not necessarily represent the Air Force or the Department of Defense.

Reprint requests to Richard A. Hoefer, Jr, DO, 4003 Kresge Way, Suite 224, Louisville, KY 40207.

More than 100,000 new cases of breast cancer are diagnosed annually in the United States. Carcinoma of the breast remains a leading cause of death among women today. Despite the increasing use of conservational techniques, modified radical mastectomy remains the cornerstone therapy of primary operable breast cancer. Significantly, a wound complication develops in the early postoperative period in up to $60 \%$ of patients who undergo modified radical mastectomy. ${ }^{1}$

Despite the frequency of complications associated with this procedure, few studies of modified radical mastectomy emphasize perioperative factors and their influence on the development of postoperative complications. Those reviews that do analyze perioperative variables deal principally with radical mastectomy, which has been shown to have a higher incidence of complication than does modified radical mastectomy. ${ }^{1-5}$

In an effort to better define factors that may contribute to postoperative wound complications, we undertook a retrospective analysis of our experience. We reviewed all modified radical mastectomies performed in our institution during a 6 -year period.

\section{Method}

During the period from January 1979 to De- 
cember 1985, 141 major procedures were performed for breast malignancies at David Grant USAF Medical Center, Travis Air Force Base, Calif. Excluded from this analysis were 2 radical mastectomies, 18 simple mastectomies, 6 simultaneous bilateral mastectomies, and 7 segmental mastectomies. Also excluded were 7 incomplete medical records.

The remaining 101 patients had undergone modified radical mastectomy, and their medical records were evaluated for this study. A total of ten perioperative variables were considered (Table 1). Data collected included patient age, percentage of ideal body weight, ${ }^{6}$ and percentage of axillary nodes with metastatic breast cancer. Technical factors evaluated included the method of creating the skin flaps, whether the pectoralis minor muscle was resected, total number of lymph nodes excised, and estimated intraoperative blood loss. Postoperative factors analyzed included the number of days with wound drains, total volume of wound-catheter drainage, and number of days hospitalized.

Complications considered in this study were wound infection, seroma, hematoma, pneumothorax, wound necrosis, and early postoperative lymphedema. To facilitate analysis, all complications were factored together.

Statistical analysis was performed using a stepwise logistic regression method, fitting the logistic regression model to a linear model in the logit scale. Computations were performed by the BMDP (PLR) Stepwise Logistic Program in a VAX computer. The method of maximal likelihood was chosen for the estimation of parameters. The hierarchical order of variables entering the model was determined by their contribution to the improvement of the $\chi$-square value. The model was not specified in advance, nor was any variable forced to enter the model.

\section{Results}

Thirty-one complications occurred in 24 patients (Figure). Seroma formation was the most frequent complication $(10.9 \%)$. It is noteworthy that in 5 of 11 patients $(45 \%)$ with seromas wound infections also developed. Wound infections developed in a total of 9 patients $(8.9 \%)$. Positive wound cultures were seen in 8 of the 9 infections: 5 Staphylococcus aureus, 1 Pseudomonas species, 1 Klebsiella pneumoniae, and 1 Staphylococcus epidermidis. One wound clinically manifested cellulitis, but no organism was recovered on culture.

A minor degree of marginal flap necrosis requiring no specific therapy was seen in four wounds $(4 \%)$. One patient $(1 \%)$ had a significant wound slough that required a skin graft. In three patients, hematomas developed beneath the skin flaps and were evacuated within 24 hours of surgery. One of the two patients $(2 \%)$ with measurable postoperative lymphedema had mild preoperative lymphedema. One patient experienced pneumothorax, discovered on a postoperative chest x-ray film; it resolved without specific therapy.

In evaluating the patient factors, no significant differences emerged between the group with wound complications and those without wound complications. Mean age in the complications group was 54 years, compared with 55 years in those without complications (Table 2). Mean ideal body weight was calculated at $126 \%$ for those with complications, compared with $123 \%$ for those with no complications. Percentage of lymph nodes containing metastatic breast cancer was slightly higher in the group in which complications developed ( $17.2 \%$ vs $14.8 \%$ ), but this did not achieve statistical significance (Table 2).

The pectoralis minor-sparing Auchincloss technique $^{7}$ of modified radical mastectomy was used in 80 patients. The remaining 21 patients had a "Patey" modified radical mastectomy, which includes resection of the pectoralis minor muscle. ${ }^{8}$ Of the patients in whom wound complications developed, $23.8 \%(5 / 21)$ had undergone a Patey-type modified radical mastectomy. The same percentage, $23.8 \%$ (19/80), had undergone an Auchincloss-type modified radical mastectomy (Table 3 ).

Two methods were used for skin flap elevation. Electrocautery (Bovie) was used in 13 patients. In the remaining 88 patients, the skin flaps were raised by sharp, cold-knife dissection. A wound complication developed in $46.2 \%$ 


\begin{tabular}{|c|}
\hline $\begin{array}{l}\text { Table } 1 \\
\text { Perioperative Factors Evaluated in } 101 \text { Patients After } \\
\text { Modified Radical Mastectomy }\end{array}$ \\
\hline $\begin{array}{l}\text { Patient factors } \\
\text { Age } \\
\text { Percentage of ideal body weight } \\
\text { Percentage of axillary nodes with metastases }\end{array}$ \\
\hline $\begin{array}{l}\text { Technical factors } \\
\text { Method of raising the skin flaps } \\
\text { (sharp, cold-knife vs Bovie electrocautery) } \\
\text { Axillary dissection technique } \\
\text { (Patey vs Auchincloss) } \\
\text { Total number of lymph nodes removed } \\
\text { Estimated volume of intraoperative blood loss }\end{array}$ \\
\hline $\begin{array}{l}\text { Postoperative factors } \\
\text { Total number of days with wound drains } \\
\text { Total volume of wound drainage } \\
\text { Total number of days in the hospital }\end{array}$ \\
\hline
\end{tabular}

\begin{tabular}{|c|c|c|c|}
\hline \multicolumn{4}{|c|}{$\begin{array}{c}\text { Table } 2 \\
\text { Comparison of Patient Factors in 101 Patients With } \\
\text { and Without Complications Following Modified } \\
\text { Radical Mastectomy }\end{array}$} \\
\hline Group & $\begin{array}{c}\text { Mean } \\
\text { Age, } \\
\text { yr }\end{array}$ & $\begin{array}{c}\% \\
\text { of ideal } \\
\text { body weight }\end{array}$ & $\begin{array}{c}\% \\
\text { of positive } \\
\text { nodes }\end{array}$ \\
\hline With complication & 54 & 126 & 17.2 \\
\hline Without complication & 55 & 123 & 14.8 \\
\hline
\end{tabular}

\section{Table 3}

Comparison of Technical Factors in 101 Patients With and Without Complications Following Modified Radical Mastectomy

\begin{tabular}{|c|c|c|c|c|c|}
\hline \multirow[b]{2}{*}{ Group } & \multirow{2}{*}{$\begin{array}{l}\text { Mean No. } \\
\text { of nodes } \\
\text { recovered }\end{array}$} & \multirow{2}{*}{$\begin{array}{c}\text { Pectoralis } \\
\text { excised, } \\
\%\end{array}$} & \multicolumn{2}{|c|}{ Knife used, \% } & \multirow{2}{*}{$\begin{array}{c}\text { Mean } \\
\text { volume of } \\
\text { blood loss, } \\
\text { mL }\end{array}$} \\
\hline & & & Hot & Cold & \\
\hline With complication & 18 & 23.8 & 46.2 & 20.5 & 405 \\
\hline Without complication & 19 & 23.8 & 53.8 & 79.5 & 409 \\
\hline
\end{tabular}




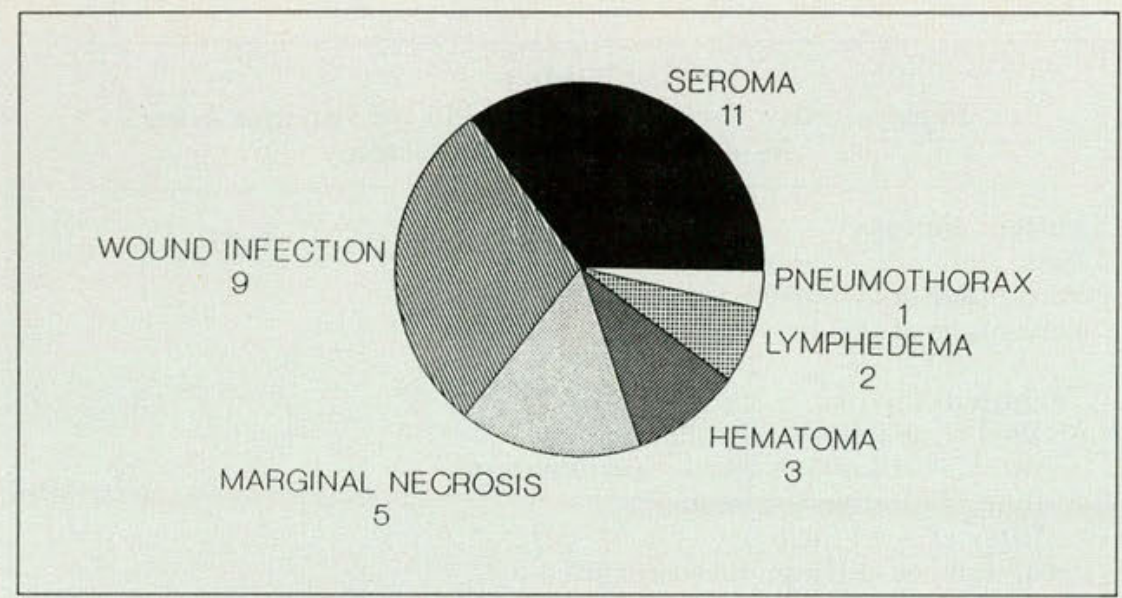

Figure. Distribution of 31 complications after 101 modified radical mastectomies.

\begin{tabular}{|lccc|}
\hline \multicolumn{4}{|c|}{$\begin{array}{c}\text { Table 4 } \\
\text { Comparison of Postoperative Factors in 101 Patients } \\
\text { With and Without Complications Following } \\
\text { Modified Radical Mastectomy }\end{array}$} \\
\hline Group & $\begin{array}{c}\text { Mean } \\
\text { volume } \\
\text { of wound } \\
\text { drainage, } \mathrm{mL}\end{array}$ & $\begin{array}{c}\text { Mean } \\
\text { No. of } \\
\text { days with } \\
\text { drain }\end{array}$ & $\begin{array}{c}\text { Mean } \\
\text { No. of } \\
\text { days in } \\
\text { hospital }\end{array}$ \\
\hline $\begin{array}{l}\text { With complication } \\
\text { Without complication }\end{array}$ & 786 & 8 & 19 \\
\hline
\end{tabular}

(6/13) of those who had had electrocautery flap elevation. The rate of wound complication was $20.5 \%$ (18/88) with sharp, cold-knife dissection (Table 3).

Estimated blood loss during surgery was comparable for both groups, with a mean of 405 $\mathrm{mL}$ for those with complications and $409 \mathrm{~mL}$ for those without complications.

Applying the stepwise logistic regression model to the ten variables studied, two factors proved significant: the length of postoperative hospital stay and the technique used to elevate the mastectomy flaps. At the first step of the run, the variable hospital days was entered into the model, increasing the log likelihood by 4.077 . The improved $\chi$-square was 8.153 , with 1 degree of freedom $(P=.004)$. At the second step, the variable flap technique (use of cold knife or electrocautery) was entered into the model. The improved $\chi$-square was 8.168 , with 1 degree of freedom $(P=.023)$.

This analysis suggests that the technique used to create the mastectomy flaps has a significant effect on the development of a postoperative wound complication. The probability of a postoperative complication following sharp 
dissection was .320 . However, when electrocautery was used in flap elevation, the probability of a complication rose to .462 , an increase of $44 \%(P=.05)$.

An increase in length of hospital stay is a logical consequence of a postoperative wound complication. This fact was supported by the patients' records, which indicated that they were kept in the hospital for management or observation of the complication.

When hospital days and flap technique were removed from the model and the program applied to the remaining independent variables, no other factors proved contributory to the development of a postoperative wound complication following modified radical mastectomy.

\section{Discussion}

Postoperative wound complications following modified radical mastectomy occur with such frequency that some complications are seen more as an "unavoidable nuisance, rather than a serious complication." 2 However, the development of even "minor" complications, such as seroma, can lead to more serious problems, including marginal necrosis, infection, and lymphedema with attendant long-term problems. ${ }^{9}$

When evaluating patient factors in wound complications, some authors ${ }^{1,5,10}$ have identified advanced age as contributing to an increase in the incidence of local wound complications. This association was not borne out in our study. The mean age in the group with complications was 54 years, with a range from 34 to 68 years; the mean age in the group without complications was 55 years, with a range from 31 to 84 years.

Obesity also has been cited in several studies $^{1,2,10}$ as being associated with increased postoperative complications. Evaluation of our patients showed that a significant number of patients in both groups exceeded the ideal body weight required by the Air Force. The mean ideal body weight percentage of the group with complications was $126 \%$, compared with that of $123 \%$ in the group without complications. Subjected to multivariate analysis, obesity failed to be associated with postoperative morbidity.
The extent of regional nodal metastases also failed to be linked with postoperative wound complications. Although we suspected that greater metastatic involvement of axillary lymph nodes might be indicative of decreased local or systemic immunocompetence, and thus predispose to infection, the data did not support this suspicion. ${ }^{11,12}$ Additionally, local lymphatic obstruction by tumor cells might cause fluid collection under mastectomy flaps, as well as lymphedema. Despite the tendency toward greater metastatic nodal involvement in the group with complications $(17.2 \%$ of nodes involved vs $14.8 \%$ in the group without complications), this difference did not achieve statistical significance.

In evaluating the importance of technical factors to wound complications, Pickren and associates $^{7}$ and Aitken and colleagues ${ }^{13}$ have suggested that axillary dissection contributes to postoperative morbidity. This may be related to increased dead space within the axilla, as well as shear forces created by arm motion and respiration, preventing proper healing of the flaps. To assess the relevance of axillary dissection to postoperative morbidity, we chose the number of lymph nodes recovered during modified radical mastectomy as an objective measurement of axillary dissection, realizing that this is, at best, a very rough measurement of the extent of dissection. In this series of patients, the mean number of nodes removed was 18 in the group with complications, compared with 19 in the group with no complications, thus eliminating the number of nodes removed as a factor in the development of a postoperative wound complication.

Another indicator of the extent of axillary dissection was whether the pectoralis minor muscle was resected with the contents of the axilla. Our study showed that the technique of axillary dissection (removal or preservation of the pectoralis minor), did not increase or decrease the chance of a complication developing.

The statistical model clearly demonstrated an increased likelihood of early wound complications when electrocautery was used to elevate skin flaps. It is unclear whether this in- 
creased morbidity is related to increased fibrosis as reported by Kakos and James ${ }^{14}$ or to some other cause. An alternate hypothesis is that Bovie electrocautery causes greater thrombosis of subdermal vessels, leading to relative flap ischemia, and resultant complications.

Furthermore, inadequately sealed lymphatics may prolong lymphatic leakage, predisposing to fluid accumulation under the skin flaps. Alexander and associates ${ }^{15}$ have postulated that fluid collection may predispose to wound infection secondary to decreased opsonic proteins in the fluid. Because wound infections developed in $45 \%$ of patients with seromas as compared with a wound infection rate of $4.4 \%$ in those without seromas, our experience empirically supports this latter finding. Cruse and Foord ${ }^{10}$ demonstrated an almost doubled incidence of wound infection during clean surgical procedures when Bovie electrocautery was used. Wound infections subsequently developed in 3 of $13(23.1 \%)$ of the patients in our series who had undergone modified radical mastectomy with Bovie dissection of skin flaps. In contrast, infections developed in only 5 of $88(5.7 \%)$ of those patients who had had sharp, cold-knife dissection. Interestingly, the incidence of seroma was considerably greater in patients who had had Bovie elevation of flaps (30\% compared with $9.1 \%$ in those who had had sharp dissection).

Despite the similarity of other perioperative factors, early wound complications subsequently developed in $46 \%$ of patients who had had flaps raised by electrocautery compared with a wound complication rate of $20.4 \%$ for patients whose flaps had been raised by sharp dissection. An increased frequency $(5.7 \%)$ of marginal necrosis with sharp dissection was noted. No patients who had had Bovie dissection experienced this complication.

Intraoperative blood loss was essentially the same for the group that had complications as for the group without postoperative complications ( $405 \mathrm{~mL}$ and $409 \mathrm{~mL}$, respectively).

Evaluation of three postoperative factorsnumber of days of hospitalization following surgery, number of days of wound-catheter presence, and volume of wound-catheter drainage- demonstrated that only the number of postoperative hospital days gained statistical significance. Patients with complications were hospitalized an average of 19 days; those without complications were hospitalized an average of 13 days (Table 4). The difference represents a relatively long period of hospital care to manage or observe a wound complication. In retrospect, we suggest that the majority of complications experienced by these patients might have been easily managed in an outpatient setting. Most of these modified radical mastectomy patients could have been discharged on their second or third postoperative day with the wound catheters in place, to be seen for follow-up in an outpatient setting. Early discharge might add the benefit of avoiding nosocomial infections.

\section{Summary}

A retrospective chart review of 101 consecutive patients who had had modified radical mastectomy was undertaken. Ten perioperative factors were evaluated for their potential contribution to postoperative wound complications. The use of electrocautery to raise skin flaps significantly increased the frequency of wound complications. Associated with wound complications, but not necessarily a causative factor, was an increased hospital stay.

Suggestions for future research might encompass wound complication and its relationship to the type of biopsy, the time elapsed between biopsy and mastectomy, use of perioperative antibiotics, skin flap thickness, and other local factors. ${ }^{16}$ We acknowledge the inherent limitations of chart review, and we recommend prospective studies to more clearly identify the role of perioperative factors in the development of wound complications following modified radical mastectomy.

Statistical analysis was performed by Rahomon Azari, PhD, department of statistics, University of California at Davis, Davis, Calif.

1. Ashikari RH: Modified radical mastectomy. Surg Clin North Am 1984;64:1095-1102.

2. Aitken DR, Minton JP: Complications associated with mastectomy. Surg Clin North Am 1983;63:1331-1352. 
3. Budd DC, Cochran RC, Sturtz DL, et al: Surgical morbidity after mastectomy operations. Am J Surg 1978;135:218-220.

4. Feigenberg Z, Zer M, Dintsman M: Comparison of postoperative complications following radical and modified radical mastectomy. World J Surg 1977;1:207-211.

5. Say CC, Donegan W: A biostatistical evaluation of complications from mastectomy. Surg Gynecol Obstet 1974;138:370-376.

6. Air Force Form 1644, Weight Standards for Men and Women.

7. Pickren JW, Rube J, Auchincloss HJ Jr: Modification of the conventional radical mastectomy. Cancer 1965;18:942-949.

8. Patey DH, Dyson WH: Prognosis of carcinoma of the breast in relation to the type of operation performed. $\mathrm{Br} J$ Cancer 1948;2:7-13.

9. Halsted WS: The swelling of the arm after operations for cancer of the breast - elephantiasis chirurgica-Its cause and prevention. Bull Johns Hopkins Hosp 1921;32:309-313.

10. Cruse PJE, Foord R: A five-year prospective study of 23,649 surgical wounds. Arch Surg 1973:107:206-210

11. Baum M, Sumner D, Edwards $\mathrm{MH}$, et al: Macrophage phagocytic activity in patients with breast cancer. $B r J$ Surg 1973;60:899-900.

12. Cruse PJE: Surgical wound sepsis. Can Med Assoc J 1970;102:251-258.

13. Aitken DR, Hunsaker R, James AG: Prevention of seromas following mastectomy and axillary dissection. Surg Gynecol Obstet $1984 ; 327-330$.

14. Kakos GS, James AG: The use of cautery in "bloodless" radical mastectomy. Cancer 1970;26:666-668.

15. Alexander JW, Korelitz J, Alexander NS: Prevention of wound infections: A case for closed suction drainage to remove wound fluids deficient in opsonic proteins. Am $J$ Surg 1976;132:59-63.

16. Beatty JD, Robinson GV, Zaia JA, et al: A prospective analysis of nosocomial wound infection after mastectomy. Arch Surg 1983;118:1421-1424. 